\title{
ATMOSPHERIC METHANE
}

\section{Shifting sources}

Atmospheric concentrations of methane a potent greenhouse gas - have been rising steadily since the Industrial Revolution. This steady rise was, however, interrupted by a plateau in methane concentrations between 1999 and 2006. The cause of this plateau is the subject of some debate as the amount of methane in the atmosphere is controlled by both the magnitude of methane emissions and the availability of reactants to break that methane down. A full account of the methane budget over this interval therefore requires an understanding of how much methane was being produced by various sources, as well as the availability of atmospheric chemicals that decompose methane.

The carbon isotopic composition of the methane can go some way to identify the sources of methane to the atmosphere; the largest sources - fossil fuel burning, biomass burning, and agriculture and wetland emissions each produce methane with a different isotopic composition. Hinrich Schaefer and colleagues utilize measurements of the isotopic composition of methane contained in ice cores and archived air samples as well as the composition as recorded by a network of monitoring stations to isolate the factors that contributed to the methane plateau (Science 352, 80-84; 2016).

Prior to 1999, methane concentrations and isotopic composition rose in tandem, indicating increasing emissions of methane that had a relatively higher ratio of ${ }^{13} \mathrm{C}$ to ${ }^{12} \mathrm{C}$. The isotopic ratio is consistent

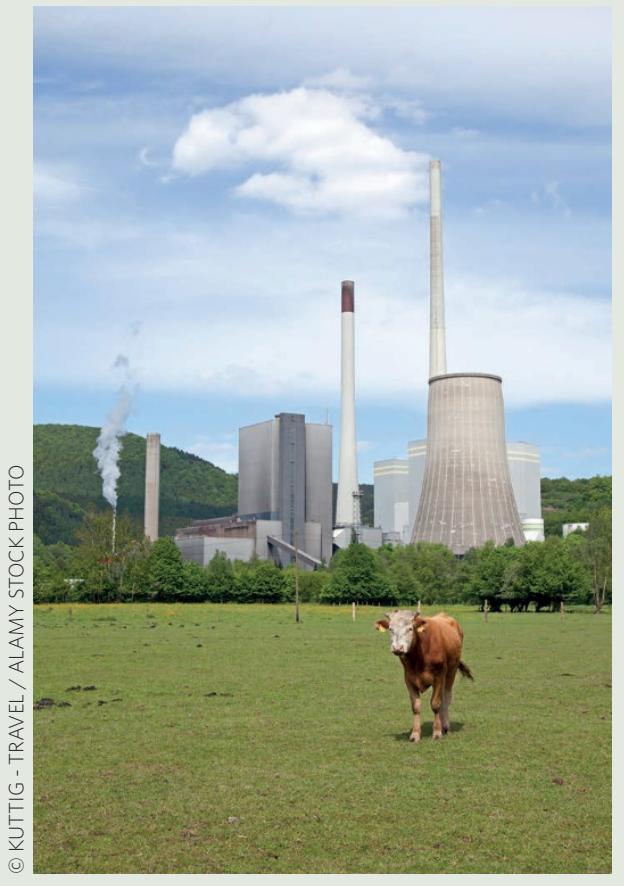

with a fossil fuel-like source. However, this trend broke down during the plateau period and, after 2006, methane concentrations started to rise again while the isotopic composition fell. This indicates that the methane being emitted had a lower amount of ${ }^{13} \mathrm{C}$, consistent with methane derived from biogenic sources. Box-modelling efforts confirm that the observed trend is best explained by a reduction in fossil fuel-related emissions starting between 1992 and 1993, with possible contributions by changes in atmospheric reactants, namely hydroxyls, whereas the rise in methane concentrations following 2006 is best explained by an increase in biogenic emissions.

Unfortunately, carbon isotopes are not able to readily distinguish between different biogenic sources of methane, for instance ruminant livestock, rice cultivation, tropical wetlands and Arctic permafrost. However, satellite methane measurements rule out any substantial emissions increases in the high latitudes; tropical climate changes over this time would be expected to increase wetland emissions, but not in the areas where the greatest emissions were observed. In contrast, increases in livestock inventories and rice cultivation have been reported for this interval, and methane inventories record increasing methane emissions from agriculture between 2000 and 2006. Thus, it perhaps isn't surprising that agriculture is having such a large influence on atmospheric methane concentrations.

It is, however, surprising that fossil fuels seem to have less of a contribution, especially given the recent exploitation of both coal and unconventional gas reserves. This finding suggests that carbon budgeting - and mitigation efforts - must closely consider the expansion of agriculture, particularly if the trend towards increased global meat consumption continues.

\section{EARTHQUAKES}

\section{Megathrusts and mountain building}

Coastlines above subduction zones slowly emerge from the sea despite repeated drowning by great, shallow earthquakes. Analysis of the Chilean coast suggests that moderate-to-large, deeper earthquakes may be responsible for the net uplift.

\section{Rich Briggs}

harles Darwin was awed and delighted by metres of sudden coastal uplift that accompanied the Concepción earthquake in Chile in 1835. In typical fashion, he posed a startling but clear hypothesis that the high elevation of coastal islands, and by inference the Andes Mountains themselves, had been "effected by

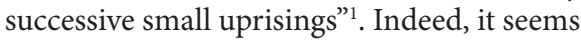
intuitive that massive offshore earthquakes could build mighty onshore mountains. Yet, the largest subduction zone earthquakes great earthquakes of magnitude 8 to 9 or more - typically drown coastlines. Writing in Nature Geoscience, Daniel Melnick ${ }^{2}$ 